\title{
Maize Streak Virus Coat Protein Is Karyophyllic and Facilitates Nuclear Transport of Viral DNA
}

\author{
H. Liu, ${ }^{1}$ M. I. Boulton, ${ }^{1}$ C. L. Thomas, ${ }^{1}$ D. A. M. Prior, ${ }^{2}$ K. J. Oparka, ${ }^{2}$ and J. W. Davies ${ }^{1}$ \\ ${ }^{1}$ Department of Virus Research, John Innes Centre, Colney Lane, Norwich NR4 7UH, U.K.; ${ }^{2}$ Scottish Crop \\ Research Institute, Invergowrie, Dundee DD2 5DA, U.K. \\ Accepted 7 June 1999.
}

\begin{abstract}
Transport of maize streak virus (MSV) DNA into the nucleus of host cells is essential for virus replication and the presence of virus particles in the nuclei of infected cells implies that coat protein (CP) must enter the nucleus. To see if $\mathrm{CP}$ is imported into the nucleus in the absence of other viral gene products, the MSV CP gene was expressed in insect cells with a baculovirus vector system, and also in tobacco protoplasts with a cauliflower mosaic virus (CaMV) $35 \mathrm{~S}$ promoter-driven transient gene expression vector. Immunofluorescent staining showed that the $\mathrm{CP}$ accumulated in the nuclei of both insect and tobacco cells. Mutagenesis of a potential nuclear localization signal in the $\mathrm{CP}$ resulted in cytoplasmic accumulation of the mutant protein. We have shown previously that the CP binds to single-stranded (ss) and double-stranded (ds) viral DNA. To investigate if CP might also be involved in viral DNA nuclear transport, $E s$ cherichia coli-expressed CP, together with TOTO-1labeled viral ss or ds DNA, was microinjected into maize and tobacco epidermal cells. Both ss and ds DNA moved into the nucleus when co-injected with the $\mathrm{CP}$ but not with $E$. coli proteins alone. These results suggest that, in addition to entering the nucleus where it is required for encapsidation of the viral ss DNA, the MSV CP facilitates the rapid transport of viral (ss or ds) DNA into the nucleus.
\end{abstract}

Maize streak virus (MSV) is a member of the family Geminiviridae and is the type species of the genus Mastrevirus (formerly subgroup I). It has a circular, single-stranded (ss), monopartite DNA genome (Mullineaux et al. 1984; Howell 1985; Lazarowitz 1988). Like other geminiviruses, it replicates in the nucleus (Goodman 1981; Davies et al. 1987; Nagar et al. 1995) via a double-stranded (ds) intermediate that also acts as a template for bidirectional transcription (MorrisKrsinich et al. 1985; Wright et al. 1997). Of the four viralencoded proteins, the two encoded by the virion sense transcripts, MP (movement protein) and CP (coat protein), are required for virus systemic infection and subsequent disease development (Boulton et al. 1989, 1993; Lazarowitz et al. 1989).

Corresponding author: Margaret I. Boulton

E-mail: margaret.boulton@bbsrc.ac.uk

Current address of H. Liu: School of Biomedical Sciences, University of St. Andrews, Irvine Building, North Street, St. Andrews, Fife, KY16 9AL, Scotland.
MSV or MSV DNA must move in some form from cell to cell and long distance to establish a systemic infection, as with other plant viruses (reviewed by Carrington et al. 1996 and Gilbertson and Lucas 1996). However, because MSV replicates in the nucleus, an initial step in the invasion of the first cell is likely to be the translocation of viral ss DNA to the nucleus and nuclear import of viral DNA must then occur in each subsequently infected cell. The respective roles of the MP and CP in MSV movement are not yet understood. Deletion or mutation of the CP gene abolished the infectivity of MSV in maize and prevented the accumulation of ss DNA in protoplasts (Boulton et al. 1989, 1993). Analysis of the interaction of Escherichia coli-expressed CP with viral DNA in vitro showed that the $\mathrm{CP}$ bound to both ss and ds DNA in a sequence-non-specific manner. Thus, in addition to its role in encapsidation, the CP might play a role in viral ss or ds DNA transport (Liu et al. 1997). Mutant MSV genomes unable to express the MP are able to replicate normally and become encapsidated in maize protoplasts but are unable to infect plants (Boulton et al. 1989, 1993; Mullineaux et al. 1988). The reported association of the MP with plasmodesmata, identified by immunoelectron microscopy, supports its role in cell-tocell movement (Dickinson et al. 1996).

Studies on the geminiviruses with bipartite genomes (species of the genus Begomovirus, formerly known as subgroup III) have revealed that the BV1 (or BR1) and BC1 (BL1) proteins, encoded on DNA B, are involved in virus movement. Following microinjection of mesophyll cells of tobacco and bean, the bean dwarf mosaic virus (BDMV) BV1 protein was able to relocate both ss and ds DNA from the nucleus to the cytoplasm but did not itself accumulate in the nucleus (Noueiry et al. 1994), whereas the equivalent protein of squash leaf curl virus (SqLCV) was shown to bind ss DNA and accumulated in the nuclei of infected plant cells and in insect cells when overexpressed from a baculovirus vector. The nuclear accumulation was assigned to two nuclear localization signal (NLS) sequences located within the $113 \mathrm{~N}$ terminal amino acids of BV1 (Pascal et al. 1994; Sanderfoot et al. 1996). A bipartite, NLS-like sequence similar to that identified for the maize regulatory protein, Opaque-2 (Varagona et al. 1992), is present in the N-terminal region of the MSV CP (Liu 1997). The BDMV BC1 protein moved from cell to cell, increased the size exclusion limit (SEL) of plasmodesmata, and mediated the cell-to-cell movement of ss and ds DNA in microinjected cells (Noueiry et al. 1994; Rojas et al. 1998). The role of the SqLCV BC1 in cell-to-cell movement was 
further endorsed when the protein was shown to be associated with endoplasmic reticulum-derived tubules that extend across the walls of procambial cells in infected tissue (Ward et al. 1997). A complex regulation of the directionality of protein translocation (and, presumably, a geminivirus nucleoprotein complex) was suggested when Sanderfoot and Lazarowitz (1995) showed that the SqLCV BC1 protein interacted with $\mathrm{BV} 1$ to redirect it from the nucleus to the cell periphery, thereby providing a mechanism for nuclear shuttling of the viral DNA and for cell-to-cell trafficking (Sanderfoot et al. 1996). Although the CP of the mastreviruses is essential for systemic infection, that of the begomoviruses is not. However, the requirements for MSV intra- and intercellular movement are likely to be similar to those of the begomoviruses and, therefore, in the absence of DNA B-encoded proteins, it is likely that the MSV CP and MP may have functions analogous to those of BV1 and $\mathrm{BC} 1$, although their structure and modus operandi may be different.

In this study, CP was overexpressed in tobacco and insect cells and its localization was determined. Microinjection of tobacco and maize cells was used to investigate the ability of E. coli-expressed CP to influence the transport of MSV DNA to the nucleus. The results show that $\mathrm{CP}$ accumulates in the nucleus and facilitates the rapid translocation of viral ds and ss DNA to the nucleus. The implications of these results are discussed with respect to the virus infection cycle.

\section{RESULTS}

\section{MSV CP accumulates in the nuclei of insect cells and tobacco protoplasts.}

Immunofluorescent staining with an FITC-conjugated second antibody was used to determine the location of MSV CP expressed from a baculovirus vector in Spodoptera frugiperda (Sf21) cells or following transient expression from a plant gene expression vector in tobacco protoplasts. Approximately $10 \%$ of the protoplasts sampled $48 \mathrm{~h}$ after transfection with the vector carrying the $\mathrm{CP}$ gene (pJITMSVCP) showed a fluorescent signal (Fig. 1A) whereas none was observed in protoplasts transfected with the vector alone (pJIT163, Fig. 1B). The locations of the FITC- and DAPI-derived fluorescence were similar (compare Figure 1A and C), showing that MSV $\mathrm{CP}$ accumulated mainly in the nucleus, although a small amount could be detected in the cytoplasm in most transfected cells.

Immunofluorescent staining of the Sf 21 cells infected with the baculovirus containing the MSV CP gene showed that approximately $95 \%$ gave a fluorescent signal 18 to $24 \mathrm{~h}$ post inoculation (p.i.; Fig. 1E), suggesting that infection with the recombinant viruses was highly efficient. No fluorescence was observed in noninfected cells or in cells infected with a wildtype baculovirus (Fig. 1F). As shown for the tobacco protoplasts, the FITC and DAPI fluorescence co-localized (not presented), confirming accumulation of $\mathrm{CP}$ in the nucleus of Sf21 cells. Cells sampled after longer incubation (48 to $72 \mathrm{~h}$ p.i.) showed increasing amounts of fluorescence in the cytoplasm, although nuclear fluorescence was still evident (not shown). The FITC fluorescence was brighter in insect cells than protoplasts, suggesting higher expression from the baculovirus vector, a finding supported by Western blot (immunoblot) analysis of cellular protein extracts (not shown).

\section{Mutation of the NLS sequence abolishes nuclear accumulation of MSV CP.}

To determine whether the putative NLS sequence present at the $\mathrm{N}$ terminus of the MSV CP is necessary for nuclear accumulation, Sf21 cells infected with baculovirus containing the CP201 (the CP product lacks the $20 \mathrm{~N}$-terminal amino acids) or CPNLSm (the CP product has a disrupted NLS and is described in the Materials and Methods section) mutant genes were examined after immunofluorescent staining. Mutant protein CP201 was present only in the cytoplasm of cells and no fluorescence was observed in the nuclei (Fig. 1G,H). An identical localization pattern was seen in cells expressing the NLS mutant (not shown).

\section{MSV CP translocates viral DNA into the nucleus.}

To investigate whether the $\mathrm{CP}$ is able to translocate viral DNA into the nucleus, the viral circular ss or linear ds DNA was labeled with the fluorescent dye TOTO-1. After incubation with $E$. coli-expressed purified CP (or with a CP nonexpressing extract or no added protein as controls), the mixtures were injected into tobacco and maize epidermal cells. The results are shown in Table 1. Injections were regarded as successful when Texas Red (TR) dextran could be visualized in the nucleus and in the streaming cytoplasm. Injection of maize was more difficult than tobacco, because of its tougher cuticle and the smaller size of the cells, especially in younger leaves. Successful injection was most frequent with the fully expanded part of leaf five from plants that had eight to nine emergent leaves. Maize tissue exhibited significantly more autofluorescence than tobacco. When the CP was present, fluorescently labeled MSV ss DNA was transported into the nucleus in all of the successfully injected tobacco (Fig. 2A) or maize (Fig. 2I) epidermal cells. In contrast, no fluorescence was seen in cells injected with TOTO-1-DNA alone (not shown) or plus E. coli proteins (Fig. 2B,J), suggesting that $\mathrm{CP}$ was a mediator of MSV DNA translocation into the nucleus. Similar results were obtained with MSV ds DNA. In the presence of $\mathrm{CP}$ (Fig. 2C,K) fluorescence was seen in tobacco and maize nuclei within 5 min after injection, and within $15 \mathrm{~min}$ the injected TOTO DNA was clearly present in the nucleus, rather than the cytoplasm, indicating that the majority of the DNA was imported rapidly into the nucleus in both species. Injection of maize mesophyll cells was not successful; the low-molecular-weight dyes (fluorescein or TR) either diffused into the vacuole and throughout the cell, or failed to move from cell to cell. Removal of the epidermis from maize leaves was difficult and it is likely that the mesophyll cells were damaged during the procedure.

\section{DISCUSSION}

Immunofluorescent staining of Sf21 insect cells infected with a recombinant baculovirus carrying the MSV CP gene showed that the expressed CP was imported into the nucleus. However, as increasing amounts of the $\mathrm{CP}$ accumulated, fluorescence was also observed in the cytoplasm, resulting in the whole cell fluorescing brightly. At the later stage of baculovirus infection, the nuclear membrane might become more permeable, resulting in increased diffusion of proteins (including $\mathrm{CP}$ ) from the nucleus (nuclear disintegration is a feature of the late stage of baculovirus infection; King and Possee 1992). 

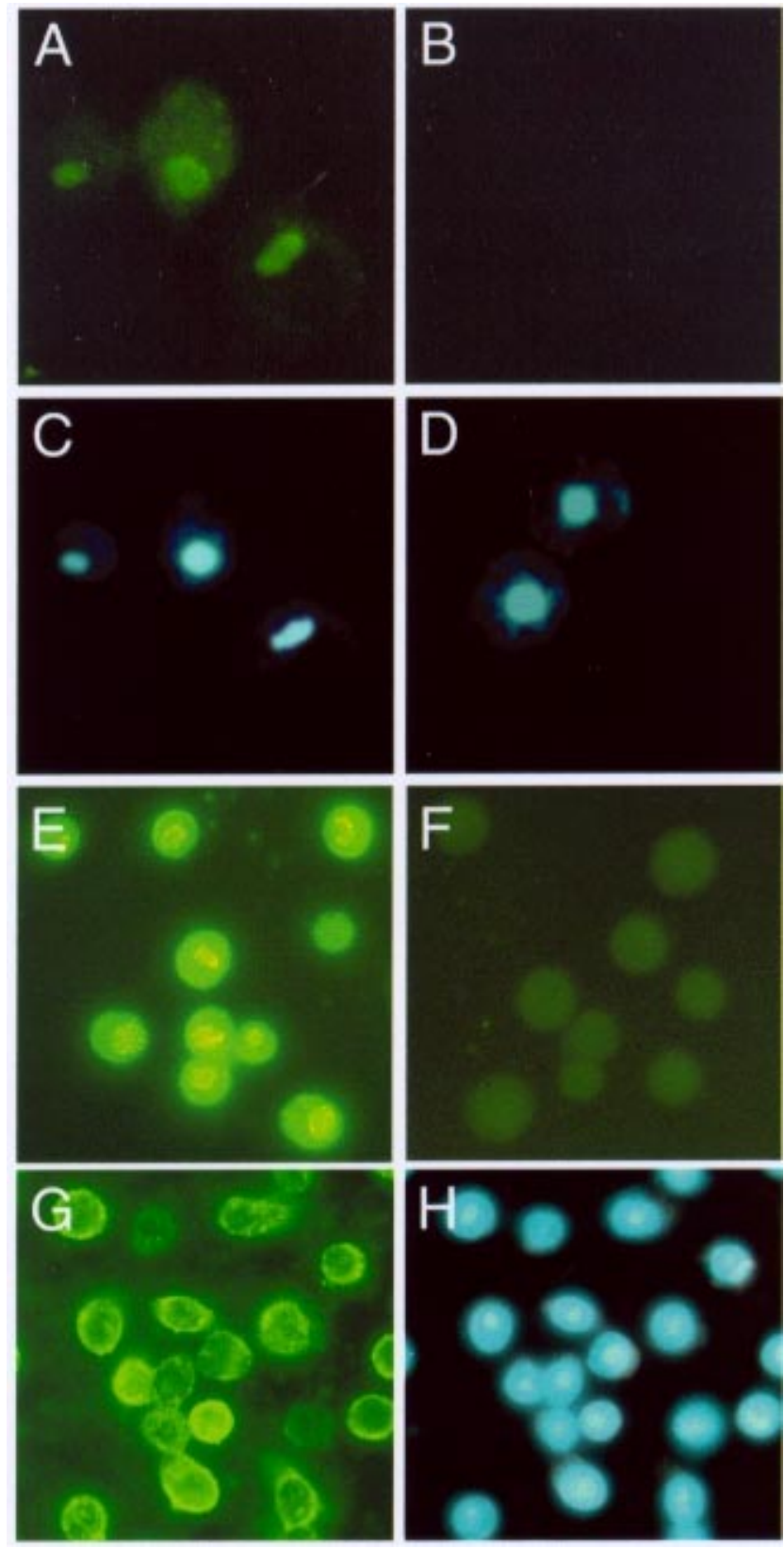

Fig. 1. Subcellular localization of maize streak virus coat protein (MSV $\mathrm{CP})$ in (A-D) tobacco protoplasts and ( $\mathbf{E}-\mathbf{H}) \mathrm{Sf} 21$ cells determined by immunofluorescent staining. A-D, BY2 tobacco protoplasts were transfected with $(\mathbf{A}, \mathbf{C})$ pJITMSVCP or $(\mathbf{B}, \mathbf{D})$ pJIT163 and sampled after 48 $\mathrm{h}$ incubation. A and B, Fluorescein isothiocyanate (FITC) fluorescence is identified by excitation at $488 \mathrm{~nm}$, and indicates location of CP. C and D, Images of the same cells, photographed after excitation at $366 \mathrm{~nm}$, to show 4.6-diamidine-2-phenylindole dihydrochloride (DAPI) fluorescence, indicating nuclei location. E-H, Sf21 insect cells were infected either with recombinant virus containing (E) the wild-type (wt) $\mathrm{CP}$ sequence or $(\mathbf{G}, \mathbf{H})$ mutant CP201, or (F) with wt baculovirus. Cells were sampled $30 \mathrm{~h}$ post inoculation. Presence of wt or mutant $\mathrm{CP}$ is identified by fluorescence at $488 \mathrm{~nm}$ excitation ( $\mathbf{E}$ and $\mathbf{G})$. For wt CP, most of the FITC signal was present in nuclei, whereas for mutant CP201, comparison of the images produced at 488 and $366 \mathrm{~nm}$ ( $\mathbf{G}$ and $\mathbf{H}$, which depict the same cells) showed that the mutant protein did not accumulate in nuclei. Nuclei were identified by DAPI staining and excitation at 366 $\mathrm{nm}(\mathbf{H})$, the nuclei staining intensely, but less intense staining was always seen in surrounding insect cell cytoplasm.
Alternatively, the cytoplasmic fluorescence may reflect an overload of the cellular nuclear import system following overexpression of a single protein, since there is clear evidence for specificity in protein import pathways (Görlich and Mattaj 1996). The localization of CP in the nucleus of both insect cells and tobacco protoplasts is compatible with reports of the accumulation of MSV particles in the nuclei of cells of infected monocots (Pinner et al. 1993), and the accumulation of $\mathrm{CP}$ in the nucleus of rice callus transformed with pJITMSVCP (M. Boulton, unpublished data), and shows that the nuclear localization of MSV CP is not host specific. MSV does not naturally infect tobacco, but is present in most cells of the mature maize leaf (Lucy et al. 1996). The nuclear transport of proteins in plant, animal, and yeast cells is specified by NLSs composed of short stretches of basic amino acids (Dingwall and Laskey 1991; Boulikas 1993; Grölich and Mattaj 1996) and the mechanism is probably similar in all eukaryotic cells. Furthermore, heterologous NLSs are recognized in plant cells (Lassner et al. 1991; Howard et al. 1992). Thus, the lack of specificity of the karyophyllic MSV CP is consistent with other studies of protein nuclear import.

The requirement of the MSV CP NLS sequence for nuclear accumulation of the CP correlates with the findings of Kunik et al. (1998), who reported nuclear import of the CP of tomato yellow leaf curl geminivirus (TYLCV) in injected Drosophila

Table 1. Effect of maize streak virus coat protein (MSV CP) on nuclear transport of MSV TOTO-DNA

\begin{tabular}{lcccc}
\hline $\begin{array}{l}\text { Plant } \\
\text { cells }\end{array}$ & $\begin{array}{c}\text { Sample } \\
\text { injected }^{\text {a }}\end{array}$ & $\begin{array}{c}\text { No. } \\
\text { injected } \\
\text { cells }^{\text {b }}\end{array}$ & $\begin{array}{c}\text { No. cells } \\
\text { with nuclear } \\
\text { localization of } \\
\text { TOTO-1-DNA }\end{array}$ & $\begin{array}{c}\text { Time of } \\
\text { nuclear } \\
\text { fluorescence } \\
\text { (min) }\end{array}$ \\
\hline Tobacco & ss DNA & 5 & 0 & $0^{\text {d }}$ \\
& ds DNA & 5 & 0 & 0 \\
& ssDNA/CP & 5 & 5 & 5 \\
& ds DNA/CP & 5 & 5 & 5 \\
Maize & ss DNA/EP & 5 & 0 & 0 \\
& ds DNA/EP & 5 & 0 & 0 \\
& ss DNA/CP & 5 & 5 & 5 \\
& ds DNA/CP & 5 & 5 & 0 \\
& ss DNA/EP & 5 & 0 & 0 \\
\hline
\end{tabular}

a DNA was labeled with TOTO-1. $\mathrm{CP}=$ coat protein, $\mathrm{EP}=$ Escherichia coli protein: single-stranded (ss) or double-stranded (ds) MSV TOTODNA was incubated with protein prior to injection.

b Successful injections.

c Earliest time at which TOTO-1-DNA was seen in the nucleus.

${ }^{\mathrm{d}}$ When no nuclear fluorescence was seen after $5 \mathrm{~min}$, observations were repeated 15 min after injection. In none of these cases was nuclear fluorescence detected.

Fig. 2. Localization of TOTO-DNA following microinjection of (A-H) tobacco and (I-P) maize epidermal cells in presence and absence of the coat protein (CP). Cells were co-injected with TOTO single-stranded (ss) or double-stranded (ds) DNA and maize streak virus (MSV) CP or Escherichia coli proteins. All images were taken 15 min after injection. A-D and I-L, Images obtained with $488 \mathrm{~nm}$ excitation wavelength, visualizing TOTO-DNA. E-H and M-P, Images obtained with $568 \mathrm{~nm}$ excitation wavelength, visualizing the Texas Red dextran. Cells were injected with (A, E, I, M) TOTO ss DNA and CP, (B, F, J, N) TOTO-ss DNA and E. coli proteins, $(\mathbf{C}, \mathbf{G}, \mathbf{K}, \mathbf{O})$ TOTO ds DNA and CP, or (D, H, L, P) TOTO ds DNA and E. coli proteins. Arrows indicate position of nucleus in injected cell. In most images at $568 \mathrm{~nm}$, position of injection needle containing fluorescent inoculum can be seen. 

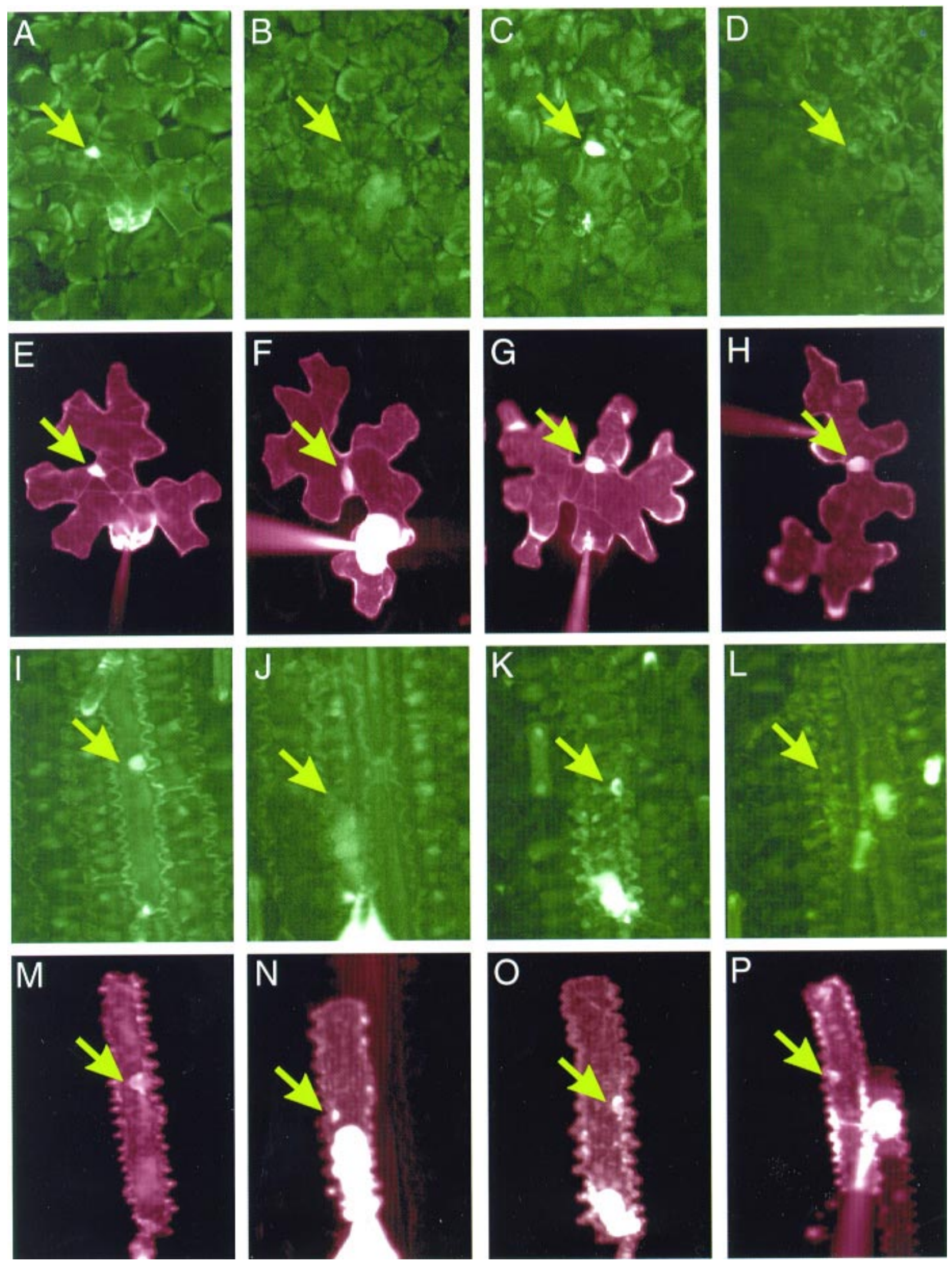

Vol. 12, No. 10, 1999 / 897 
embryo cells. A TYLCV CP- $\beta$-glucuronidase fusion protein was nuclear-localized in transfected petunia mesophyll protoplasts and the localization signal resided within the first 38 amino acids of the CP. TYLCV is a member of the genus $B e$ gomovirus but, like MSV, it has a monopartite genome and its CP NLS occupies a similar N-terminal position: amino acids 5 to 22 for MSV (Liu et al. 1997) and 3 to 20 for TYLCV (Kunik et al. 1998). However, deletion of the amino acids constituting the second domain of the bipartite NLS of TYLCV resulted in residual (but markedly decreased) nuclear localization. Such residual localization was not seen with MSVNLSm or CP201; whether this reflects the different assay systems used, or a fundamental difference between the efficiency of nuclear localization of the two CPs is not known. We have observed similar potential NLS sequences near the $\mathrm{N}$ termini of the CPs of other mastreviruses and in other begomovirus CPs (data not shown).

Microinjection showed that, despite its small size, MSV DNA alone does not efficiently accumulate in the nucleus of living plant cells. However, E. coli-expressed MSV CP (but not $E$. coli proteins) is able to act as a nuclear transporter of MSV DNA in a host-non-specific manner. We have already shown that E. coli-expressed MSV CP binds DNA in vitro and that deletion of the N-terminal 20 amino acids of the $\mathrm{CP}$ (mutant CP201) abolishes the protein-DNA binding (Liu et al. 1997). It is possible that the putative NLS sequence of the $\mathrm{CP}$ not only is involved in $\mathrm{CP}$ nuclear import but also is critical for binding to the virus DNA to facilitate its transport into the nucleus. This would be consistent with the findings of LaCasse and Lefebvre (1995), who reported that nucleic acid binding and NLS motifs overlapped in $80 \%$ of the karyophyllic nucleic acid binding proteins that they surveyed.

The microinjection experiments reported here provide direct evidence for $\mathrm{CP}$-mediated MSV DNA nuclear transport, an essential early step in the infection cycle. We have shown that circular ss DNA can be transported and it is likely that this CP-mediated import is common to all geminiviruses, at least in the first infected cell, following insect transmission of the virus. This is supported by the presence of NLS within other geminivirus CPs. Our studies do not address the form in which the viral DNA enters the nucleus; it has been reported that SV40 can be transported as a virion from the nucleus but this required the nuclear pores to be modified by virus-encoded proteins (Feldherr et al. 1994). For $\mathrm{MSV}$, the $\mathrm{CP}$ might also fulfill the role of BV1 in binding viral DNA and transporting it to the nucleus in subsequently infected cells, as suggested for BV1 of the bipartite geminiviruses, SqLCV (Pascal et al. 1994; Sanderfoot and Lazarowitz 1995; Sanderfoot et al. 1996) and BDMV (Nouiery et al. 1994). In the case of MSV, in which both ss and ds DNA are bound by the CP (Liu et al. 1997), it is not clear whether the translocation of virus DNA from infected cells to the nucleus of an uninfected cell is as a nucleoprotein complex (ds or ss DNA plus CP) or as a virion. If the BC1 role is played by MSV MP (Boulton et al. 1989; Liu et al. 1997) it will be important to see if MSV CP and MP interact and if they influence each other in their respective intra- and intercellular functions, as has been suggested for the SqLCV movement proteins (Sanderfoot and Lazarowitz 1995).

\section{MATERIALS AND METHODS}

Molecular biological procedures were carried out as described by Sambrook et al. (1989), unless stated otherwise.

\section{Purification of MSV CP expressed in E. coli.}

The expression of MSV CP in E. coli was carried out as described by Liu et al. (1997) and the E. coli-expressed CP was immunochromatographically purified with a Hydrazide AvidChrom Cartridge (Sigma, St. Louis, MO) following the protocol described in the instruction manual. To provide control samples, CP non-expressing extracts were used. Purified CP and E. coli extracts were stored at $-70^{\circ} \mathrm{C}$ and used for microinjection at a concentration of $0.5 \mathrm{mg} / \mathrm{ml}$ for the $\mathrm{CP}$ extract; an equivalent volume was used for the control extract. Coomassie blue staining of the proteins separated by polyacrylamide gel electrophoresis showed only two bands for the CP extract: both were CP specific and equivalent to those seen with purified virus preparations. No bands were visible in the control extract.

\section{Localization of MSV wild-type and mutant CPS expressed in insect cells.}

For these studies, the localizations of wild-type and two mutant CPs were compared. Mutant CP201 lacks the $20 \mathrm{~N}$ terminal amino acids (Liu et al. 1997), in mutant CPNLSm a number of the basic amino acids of the NLS are substituted producing a mutated protein with the $\mathrm{N}$-terminal sequence MSTSKtnRGDDSNWSKRVTnnKPS rather than the wildtype MSTSKRKRGDDSNWSKRVTKKKPS (substituted amino acids are shown in lowercase). The Bac-to-Bac Baculovirus Expression System (Life Technologies, Gaithersburg, MD) was used to express MSV CP in cultured cells from Spodoptera frugiperda IPBL-SF-21 (Sf21 cells; Vaughn et al. 1977), which were maintained in TC-100 SSM (TC-100 supplemented with $10 \%$ fetal bovine serum [FBS] and $50 \mu \mathrm{g}$ of neomycin per $\mathrm{ml}, 62.9 \mu \mathrm{g}$ of penicillin per $\mathrm{ml}$, and $100 \mu \mathrm{g}$ of streptomycin per ml) at $27^{\circ} \mathrm{C}$ as described by King and Possee (1992). Vector pFASTBAC1 containing the polyhedrin promoter was used to transpose the $\mathrm{CP}$ gene into a baculovirus shuttle vector (bacmid), propagated in E. coli. The wild-type CP and mutant CP201 genes were released from pETCPwt and pETCP201 (Liu et al. 1997) by XbaI/BamHI digestion, made blunt-ended with Klenow fragment, and purified by gel elution. Plasmid FBMSVCP was constructed by ligating the blunt-ended $\mathrm{CP}$ gene fragments into linearized, blunt-ended pFASTBAC1 vector. Mutant pCPNLSm was constructed by polymerase chain reaction (PCR) amplification of the infectious MSV clone, pMSV-Ns (Boulton et al. 1991), as the template. The $5^{\prime}$ end primer comprised 90 nucleotides,

5'-GGC-tCt-aGA-TAA-GCt-TTC-AGC-CAT-GTC-CAC-

GTC-CAA-GAc-aAA-cCG-GGG-AGA-TGA-TTC-GAA-

TTG-GAG-TAA-GCG-GGT-GAC-TAA-cAA-cAA-GCC-3', and contained an $\mathrm{XbaI}$ site (underlined); the $3^{\prime}$ end primer, 5'CGG-CGT-Tgc-ATg-CAT-TAC-TG-3', contained an SphI site (underlined). In both cases, nucleotides differing from the wild-type MSV sequence are in lowercase. The PCR product was ligated to pGEMT (Promega, Madison, WI), its sequence confirmed, and the CPNLSm gene fragment was released by

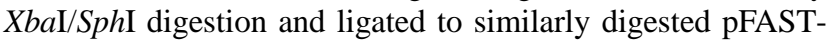
$\mathrm{BAC1}$. The transposition of the $\mathrm{CP}$ genes into the bacmid, 
transfection of Sf21 cells to obtain recombinant baculovirus, and expression of CP in monolayer-cultured Sf21cells followed the procedure described in the Bac-to-Bac supplier's instructions. The expression of each $\mathrm{CP}$ was analyzed, on a time-course basis, by sodium dodecyl sulfate-polyacrylamide gel electrophoresis, Coomassie blue staining, and Western blotting with anti-MSV CP serum as described by Maule et al. (1992). To localize the expressed CPs, Sf21 cells were cultured on a sterile microscope slide and infected with the appropriate recombinant viruses. Each slide was seeded with 0.5 $\times 10^{6} \mathrm{Sf} 21$ cells and incubated for $2 \mathrm{~h}$ at room temperature to allow the cells to attach. The medium was replaced with 200 $\mu \mathrm{l}$ of baculovirus inoculum (with a multiplicity of infection greater than 5) and incubation continued for a further $1 \mathrm{~h}$ at room temperature after which the inoculum was replaced with $500 \mu \mathrm{l}$ of TC-100 SSM. The inoculated cells were incubated for $18,24,30,48$, or $72 \mathrm{~h}$ at $27^{\circ} \mathrm{C}$ in a moistened box. The cells were fixed in acetone for $10 \mathrm{~min}$ before immunofluorescent staining. For staining, slides were incubated for $1 \mathrm{~h}$ at room temperature in blocking solution (1x PBS [phosphatebuffered saline]; 5\% dried skimmed milk) containing 1:400 diluted anti-MSV CP serum. After being washed with $1 \times$ PBS, the slides were incubated in blocking solution with 1:100 diluted fluorescein isothiocyanate (FITC)-goat antirabbit antiserum for $2 \mathrm{~h}$ at room temperature, washed, and stained with 1:1,000 diluted (in PBS) 4.6-diamidine-2phenylindole dihydrochloride (DAPI) for $10 \mathrm{~min}$. After being washed, the cells were bathed in two drops of Citifluor (Sigma) and protected by a coverslip. The cells were examined with a Nikon Microphot-sa microscope with UV excitation at $366 \mathrm{~nm}$ for DAPI or $488 \mathrm{~nm}$ for FITC staining.

\section{Localization of MSV CP transiently expressed in tobacco protoplasts.}

Protoplasts isolated from suspension cultured tobacco (BY2) cells (Nicotiana tabacum L. 'Bright Yellow 2'; Nagata et al. 1992) were used to analyze the site of MSV CP accumulation. For expression of the MSV CP, a pUC-based transient expression vector, pJITMSVCP, was constructed by ligating the blunt-ended XbaI/BamHI CP gene fragment from pETMSVCP into pJIT163 (Guerineau et al. 1992), which had been linearized by HindIII/BamHI digestion and rendered blunt-ended. A recombinant clone containing the $\mathrm{CP}$ in the correct orientation was selected and DNA was purified with a column purification kit (Qiagen, Hilden, Germany). The DNA was resuspended in sterile, distilled water and maintained as a sterile solution for protoplast transfections.

Isolation and transfection of protoplasts derived from a BY2 tobacco cell suspension culture were carried out as described by Hong and Stanley (1995). The transfected protoplasts were incubated for $48 \mathrm{~h}$ at $27^{\circ} \mathrm{C}$ and then pelleted by centrifugation at $700 \mathrm{rpm}$ (Sorvall RT 6000B; Du Pont, Wilmington, DE) for $5 \mathrm{~min}$. The protoplasts were washed twice with $0.4 \mathrm{M}$ mannitol and resuspended in a final volume of 1 $\mathrm{ml}$. For light microscopy studies to localize the $\mathrm{CP}$, protoplasts $(100 \mu \mathrm{l})$ were spread gently onto a microscope slide, dried with a hair dryer and fixed in acetone for $30 \mathrm{~min}$. After the slides were washed twice in $1 \times$ PBS containing $1 \%$ Triton $\mathrm{X}-100$ for $10 \mathrm{~min}$, the protoplasts on the slide were subjected to immunofluorescent and DAPI staining as described before. Western blotting analysis was used to assess $\mathrm{CP}$ expression.

\section{Fluorescent labeling of MSV DNA preparations.}

MSV ss and ds DNAs were used for microinjection. The ss DNA was purified by phenol:chloroform isoamyl alcohol extraction from virus particles and the ds DNA was a genomelength BamHI fragment isolated from an infectious MSV clone (pMSV-Ns; Boulton et al. 1991) by electrophoretic elution from an agarose gel. Both DNAs were resuspended to a concentration of $200 \mathrm{ng} / \mu \mathrm{l}$. For fluorescent staining of the DNA, $1 \mu \mathrm{g}$ of ss or ds DNA was incubated for $30 \mathrm{~min}$ with 1.5 $\mu \mathrm{l}$ of $(20 \mu \mathrm{M})$ TOTO-1 dye (Molecular Probes, Eugene, OR) in a total volume of $20 \mu \mathrm{l}$ to yield an average base pair:dye ratio of five (Goodwin et al. 1993). The DNA was diluted to $200 \mu \mathrm{l}$, transferred to a microconcentrator (Microcon-10, cutoff $10 \mathrm{kDa}$; Amicon, Beverly, MA) and centrifuged at 13,000 rpm (micromax centrifuge; 1 EC, Needham Heights, MA) for $30 \mathrm{~min}$ in a microcentrifuge to remove free dye molecules, resulting in a labeled DNA preparation of approximately 50 $\mathrm{ng} / \mu \mathrm{l}$. All DNA samples and staining solutions were prepared in $1 \times$ TE (Tris-EDTA) buffer. Staining solutions were prepared daily, immediately before use.

\section{Microinjection and microscopy.}

The upper epidermal cells of tobacco and maize leaves and the mesophyll cells of maize were used for injection. Tobacco (Nicotiana tabacum cv. Xanthi) was grown for 4 weeks and maize (Zea mays cv. Golden Bantam $\times$ Yellow hybrid) for 2 to 6 weeks at $25^{\circ} \mathrm{C}$ with a $16-\mathrm{h}$ photoperiod. Injection was attempted for maize at different ages from 2 to 6 weeks after planting. Injection of tobacco was carried out essentially as described by Oparka et al. (1997), with fully expanded detached leaves and $10 \mathrm{mM}$ sucrose as osmoticum. Leaves were secured to a glass plate and the epidermal cells were injected. For injection of maize epidermal cells, the cut edge of the detached leaf was covered with Whatman $3 \mathrm{MM}$ paper soaked in $10 \mathrm{mM}$ sucrose. To inject maize mesophyll cells, leaves were kept at room temperature for $30 \mathrm{~min}$, after which the lower epidermis was removed from the edge of the segment and 10 $\mathrm{mM}$ sucrose was applied to the exposed region (Fujiwara et al. 1993). In all injections, $10-\mathrm{kDa}$ TR dextran was included, to monitor the position of the needle during the injection and to locate the position of the nucleus as described in Oparka et al. (1997). A small molecular dye (either TR or fluorescein) was injected to confirm the integrity of the cell-to-cell connections. All dyes were obtained from Molecular Probes. Fluorescence was monitored with a Bio-Rad MRC 1000 confocal laser scanning microscope equipped with a $25 \mathrm{~mW}$ krypton/argon laser. Images were recorded immediately after injection and at 5, 10, and $15 \mathrm{~min}$ after injection. For TR dextran imaging, excitation at $568 \mathrm{~nm}$ was used; for TOTO-1 (and therefore the labeled DNA), blue excitation at $488 \mathrm{~nm}$.

To investigate the function of MSV CP in virus DNA nuclear transport, the $\mathrm{CP}$ or E. coli extracts and TOTO-1-ss or TOTO-1-ds DNA were mixed in a ratio of 1:1 (vol:vol), incubated at room temperature for $15 \mathrm{~min}$, and then injected with an equal volume of TR dextran. For injection of DNA alone, the TOTO-labeled DNA was incubated with an equal volume of $1 \times$ TE buffer prior to injection.

\section{ACKNOWLEDGMENTS}

We would like to thank John Stanley and Andy Maule for helpful discussions and Jeremy Dix for technical help with the preparation of figures. 
K. J. O. and D. A. M. P. acknowledge the financial support of the Scottish Office Agriculture, Environment and Fisheries Department (SOAEFD). The John Innes Centre is grant-aided by the Biotechnology and Biological Sciences Research Council (BBSRC) and H. L. was in receipt of a John Innes Foundation Ph.D. studentship. MSV was held and manipulated under MAFF licenses PHL11A/2627(6/98) and PHL11/2300(6/98).

\section{LITERATURE CITED}

Boulikas, T. 1993. Nuclear localization signals (NLS). Crit. Rev. Eukaryotic Gene Expression 3:193-227.

Boulton, M. I., King, D. I., Donson, J., and Davies, J. W. 1991. Point substitutions in a promoter-like region and the V1 gene affect the host range and symptoms of maize streak virus. Virology 183:114-121.

Boulton, M. I., Pallaghy, C. K., Chatani, M., MacFarlane, S., and Davies, J. W. 1993. Replication of maize streak virus mutants in maize protoplasts: evidence for a movement protein. Virology 192:85-93.

Boulton, M. I., Steinkellner, H., Donson, J., Markham, P. G., King, D. I., and Davies, J. W. 1989. Mutational analysis of the virion-sense genes of maize streak virus. J. Gen. Virol. 70:2309-2323.

Carrington, J. C., Kasschau, K. D., Mahajan, S. K., and Schaad, M. C. 1996. Cell-to-cell and long distance transport of viruses in plants. Plant Cell 8:1669-1681.

Davies, J. W., Stanley, J., Donson, J., Mullineaux, P. M., and Boulton, M. I. 1987. Structure and replication of geminivirus genomes. J. Cell Sci. (Suppl.) 7:95-107.

Dickinson, V. J., Halder, J., and Woolston, C. J. 1996. The product of maize streak virus ORF V1 is associated with secondary plasmodesmata and is first detected with the onset of viral lesions. Virology 220: 51-59.

Dingwall, C., and Laskey, R. A. 1991. Nuclear targeting sequences - a consensus? Trends Biochem. Sci. 16:478-481.

Feldherr, C., Cole, C., Lanford, R. E., and Akin, D. 1994. The effects of SV40 large $\mathrm{T}$ antigen and p53 on nuclear transport capacity in BALB/c 3 T3 cells. Exp. Cell Res. 213:164-171.

Fujiwara, T., Giesman-Cookmeyer, D., Ding, B., Lommel, S. A., and Lucas, W J. 1993. Cell-to-cell trafficking of macromolecules through plasmodesmata potentiated by the red clover necrotic mosaic virus movement protein. Plant Cell 5:1783-1794.

Gilbertson, R. L., and Lucas, W. J. 1996. How do viruses traffic on the 'vascular highway'? Trends Plant Sci. 1:260-268.

Goodman, R. M. 1981. Geminiviruses. Pages 879-910 in: Handbook of Plant Virus Infection and Comparative Diagnosis. E. Kurstak, ed. Elsevier/North Holland Biomedical Press, New York.

Goodwin, P. M., Johnson, M. E., Martin, J. C., Ambrose, W. P., Marrone, B. L., Jett, J. H., and Keller, R. A. 1993. Rapid sizing of individual fluorescently stained DNA fragments by flow cytometry. Nucleic Acids Res. 21:803-806.

Görlich, D., and Mattaj, I. W. 1996. Nucleocytoplasmic transport. Science 271:1513-1518

Guerineau, F., Lucy, A., and Mullineaux, P. 1992. Effect of two consensus sequences preceding the translation initiator codon on gene expression in plant protoplasts. Plant Mol. Biol. 18:815-818.

Hong, Y., and Stanley, J. 1995. Regulation of African cassava mosaic virus complementary-sense gene expression by $\mathrm{N}$-terminal sequences of the replication-associated protein AC1. J. Gen. Virol. 76:2415-2422.

Howard, E. A., Zupan, J. R., Citovsky, V., and Zambryski, P. C. 1992. The VirD2 protein of A. tumefaciens contains a C-terminal bipartite nuclear localization signal: implication for nuclear uptake of DNA in plant cells. Cell 68:109-118.

Howell, S. H. 1985. Physical structure and genetic organization of the genome of maize streak virus (Kenyan isolate). Nucleic Acids Res. 13:3018-3019.

King, L. A., and Possee, R. D. 1992. The Baculovirus Expression System: A Laboratory Guide. Chapman and Hall, London. pp. 124-126 and 171-176.

Kunik, T., Palanichelvam, K., Czosnek, H., Citovsky, V., and Gafni, Y. 1998. Nuclear import of the capsid protein of tomato yellow leaf curl virus (TYLCV) in plant and insect cells. Plant J. 13:393-399.

LaCasse, E. C., and Lefebvre, Y. A. 1995. Nuclear localization signals overlap DNA- or RNA-binding domains in nucleic acid binding proteins. Nucleic Acids Res. 23, 1647-1656.

Lassner, M. W., Jones, A., Daubert, S., and Comai, L. 1991. Targeting of T7 RNA polymerase to tobacco nuclei mediated by an SV40 nuclear location signal. Plant Mol. Biol. 17:229-234.
Lazarowitz, S. G. 1988. Infectivity and complete nucleotide sequence of the genome of a South African isolate of maize streak virus. Nucleic Acids Res. 16:229-249.

Lazarowitz, S. G., Pinder, A. J., Damsteegt, V. D., and Rogers, S. G. 1989. Maize streak virus genes essential for systemic spread and symptom development. EMBO J. 8:1023-1032.

Liu, H. T. 1997. Molecular biology of maize streak virus movement in maize. Ph.D. thesis. University of East Anglia, Norwich, U.K.

Liu, H. T. , Boulton, M. I., and Davies, J. W. 1997. Maize streak virus coat protein binds single- and double-stranded DNA in vitro. J. Gen. Virol. 78:1265-1270.

Lucy, A. P., Boulton, M. I., Davies, J. W., and Maule, A. J. 1996. Tissue specificity of Zea mays infection by maize streak virus. Mol. Plant-Microbe Interact. 9:22-31.

Maule, A. J., Usmany, M., Wilson, I. G., Boudazin, G., and Vlak, J. M. 1992. Biophysical and biochemical properties of baculovirusexpressed CaMV P1 protein. Virus Genes 6: 5-18.

Morris-Krsinich, B. A. M., Mullineaux, P. M., Donson, J., Boulton, M. I., Markham, P. G., Short, M. N., and Davies, J. W. 1985. Bidirectional transcription of maize streak virus DNA and identification of the coat protein gene. Nucleic Acids Res. 13:7237-7256.

Mullineaux, P. M., Boulton, M. I., Bowyer, P., van der Vlugt, R., Marks, M., Donson, J., and Davies, J. W. 1988. Detection of a non-structural protein of $M_{\mathrm{r}} 11000$ encoded by the virion DNA of maize streak virus. Plant Mol. Biol. 11:57-66.

Mullineaux, P. M., Donson, J., Morris-Krsinich, B. A. M., Boulton, M. I., and Davies, J. W. 1984. The nucleotide sequence of maize streak virus DNA. EMBO J. 3:3063-3068.

Nagar, S., Pedersen, T. J., Carrick, K. M., Hanley-Bowdoin, L., and Robertson, D. 1995. A geminivirus induces expression of a host DNA synthesis protein in terminally differentiated plant cells. Plant Cell 7:705-719.

Nagata, T., Nemoto, Y., and Hasezawa, S. 1992. Tobacco BY-2 cell line as the 'Hela' cell in the cell biology of higher plants. Int. Rev. Cytol. 132:1-30

Noueiry, A. O., Lucas, W. J., and Gilbertson, R. L. 1994. Two proteins of a plant DNA virus coordinate nuclear and plasmodesmal transport. Cell 76:925-932.

Oparka, K. J., Prior, D. A. M., Santa Cruz, S., Padgett, H. S., and Beachy, R. N. 1997. Gating of epidermal plasmodesmata is restricted to the leading edge of expanding infection sites of tobacco mosaic virus (TMV). Plant J. 12:781-789.

Pascal, E., Sanderfoot, A. A., Ward, B. M., Medville, R., Turgeon, R., and Lazarowitz, S. G. 1994. The geminivirus BR1 movement protein binds single-stranded DNA and localizes to the cell nucleus. Plant Cell 6:995-1006.

Pinner, M. S., Medina, V., Plaskitt, L. A., and Markham, P. G. 1993. Viral inclusions in monocotyledons infected by maize streak and related viruses. Plant Pathol. 42:75-87.

Rojas, M. R., Noueiry, A. O., Lucas, W. J., and Gilbertson, R. L. 1998. Bean dwarf mosaic geminivirus movement proteins recognize DNA in a form- and size-specific manner. Cell 95:105-113.

Sambrook, J., Fritsch, E. F., and Maniatis, T. A. 1989. Molecular Cloning: A Laboratory Manual. 2nd ed. Cold Spring Harbor Laboratory, Cold Spring Harbor, NY.

Sanderfoot, A. A., Ingham, D. J., and Lazarowitz, S. G. 1996. A viral movement protein as a nuclear shuttle. Plant Physiol. 110:23-33.

Sanderfoot, A. A., and Lazarowitz, S. G. 1995. Cooperation in viral movement: The geminivirus BL1 movement protein interacts with BR1 and redirects it from the nucleus to the cell periphery. Plant Cell 7:1185-1194.

Varagona, M. J., Schmidt, R. J., and Raikhel, N. V. 1992. Nuclear localization signal(s) required for nuclear targeting of the maize regulatory protein Opaque-2. Plant Cell 4:1213-1227.

Vaughn, J. L., Goodwin, R. H., Tompkins, G. J., and MacCawley, P. 1977. The establishment of two cell lines from the insect Spodoptera frugiperda (Lepidoptera: Noctuidae). In Vitro 13:213-217.

Ward, B. M., Medville, R., Lazarowitz, S. G., and Turgeon, R. 1997. The geminivirus BL1 movement protein is associated with endoplasmic reticulum-derived tubules in developing phloem cells. J. Virol. 71:3726-3733

Wright, E. A., Heckel, T., Groenendijk, J., Davies, J. W., and Boulton, M. I. 1997. Splicing features in maize streak virus virion- and complementary-sense gene expression. Plant J. 12:1285-1297. 